\title{
ARTICLE
}

\section{Estimation of dry deposition velocities of radionuclides released by the accident at the Fukushima Dai-ichi Nuclear Power Plant}

\author{
Masanori Takeyasu* and Shuichi Sumiya \\ Japan Atomic Energy Agency, 4-33 Muramatsu, Tokai-mura, Naka-gun, Ibaraki-ken, 319-1194, Japan
}

\begin{abstract}
On the basis of environmental radiation monitoring results at the Nuclear Fuel Cycle Engineering Laboratories, Japan Atomic Energy Agency, following the Fukushima Dai-ichi Nuclear Power Plant accident, the dry deposition velocities of radionuclides on the ground were estimated. As a result, the estimated dry deposition velocities for Iodine-131, Cesium-134, Cesium-136 and Cesium-137 were in the order of $1 \mathrm{~mm} / \mathrm{s}$, and were the same order of those estimated in other studies. The estimated dry deposition velocities varied according to the variations of the ratios of the particulate and gaseous forms of their radionuclides and meteorological conditions such as wind speed.
\end{abstract}

\section{Keywords: dry deposition velocity; Iodine-131; Cesium-134; Cesium-136; Cesium-137; Fukushima Dai-ichi Nuclear Power Plant accident; Nuclear Fuel Cycle Engineering Laboratories; Tokai-mura; Ibaraki}

\section{Introduction}

The radioactive substances were released by the accident at the Fukushima Dai-ichi Nuclear Power Plant (1F-NPP) of Tokyo Electric Power Company and deposited on the ground, which caused the increase of an air dose rate. To investigate the dry deposition phenomenon is important in order to clarify the increase of the dose rate, because the air dose rate significantly increased in the south-southwest area of 1F-NPP including Tokai-mura by dry deposition of the high-concentration plume released from the night of March 14 to the morning of March 15 [1]. The process of dry deposition is driven by a variety of physical, chemical and biological factors. Further complication arises from the fact that radionuclides, when released into the atmosphere, exist in various chemical and physical states [2].

The emergency monitoring of environmental radiation including the measurement of the air concentrations of radionuclides from 13 March 2011 to 23 May 2011 and the fallout from 15 March 2011 to 2 May 2011 was performed on the Nuclear Fuel Cycle Engineering Laboratories (NCL), Japan Atomic Energy Agency (JAEA), in addition to the routine monitoring of air dose rate, meteorological condition and so on.

In this paper, the dry deposition velocities of radionuclides, which were defined as the fallout divided by the time integrated air concentration, were estimated on the basis of their monitoring results when the radioactive plumes would reach the NCL.

\footnotetext{
*Corresponding author. Email: takeyasu.masanori@jaea.go.jp
}

\section{Materials and method}

The air and the fallout samplings in addition to the routine monitoring were performed at the NCL about $115 \mathrm{~km}$ south of the 1F-NPP. The location of the NCL is shown in Figure 1.

The measuring methods of the air concentrations of radionuclides were the following: The air samples were continuously collected by a portable dust and iodine sampler (model No. PNC-800) installed at the height of $1 \mathrm{~m}$ above the ground. The dust filter (Type He-40T made by Toyo-roshi Kaisya Ltd., Japan) and charcoal cartridge impregnated by TEDA (tri-ethylene-diamine) (Type CHC-50 made by Toyo-roshi Kaisha Ltd., Japan) were replaced after every $12 \mathrm{~h}$ as a matter of principle. However, the interval between the replacements was inversely proportional to the dose rate. As a result, the interval between the replacements was from $3 \mathrm{~h}$ to $7 \mathrm{~d}$.

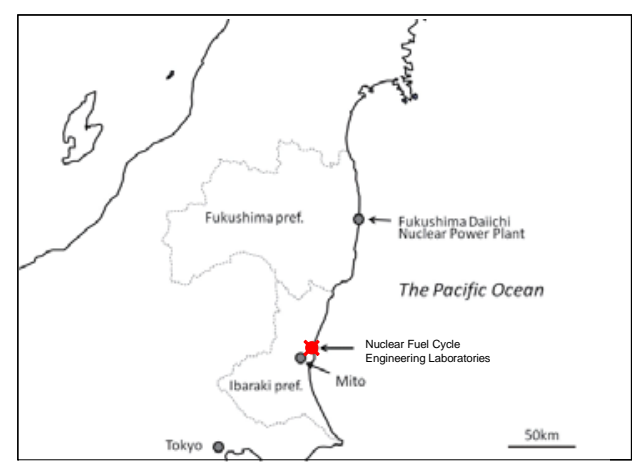

Figure 1. Location of Nuclear Fuel Cycle Engineering Laboratories, JAEA. 
The air concentrations were determined by gamma-ray spectrometry with a Ge detector. The details of the measurement procedures were described in the previous paper [3-4]. The radionuclides collected by the dust filter were considered to be particulate radionuclides, and those collected by the charcoal cartridge were considered to be gaseous radionuclides. The results of the variations of the air concentrations were shown in Figure 2.

The measuring methods of the fallout were as follows: The fallout samples were collected using a large bulk sampler covering an area of $0.5 \mathrm{~m}^{2}$. The fallout was determined by gamma-ray spectrometry with $\mathrm{Ge}$ detector. The results of the variations of the fallout were shown in Figure 3.

The routine monitoring of air dose rate, wind speed and direction, rainfall, atmospheric humidity and atmospheric stability has been continuously performed before the accident at the NCL. Figure 4 showed the variations of the dose rate measured and rainfall observed. The wind speed and direction was observed at the height of $15 \mathrm{~m}$ above the ground. Figure 5 showed the variations of the wind speed and direction. Figure 6 showed the variations of the atmospheric humidity

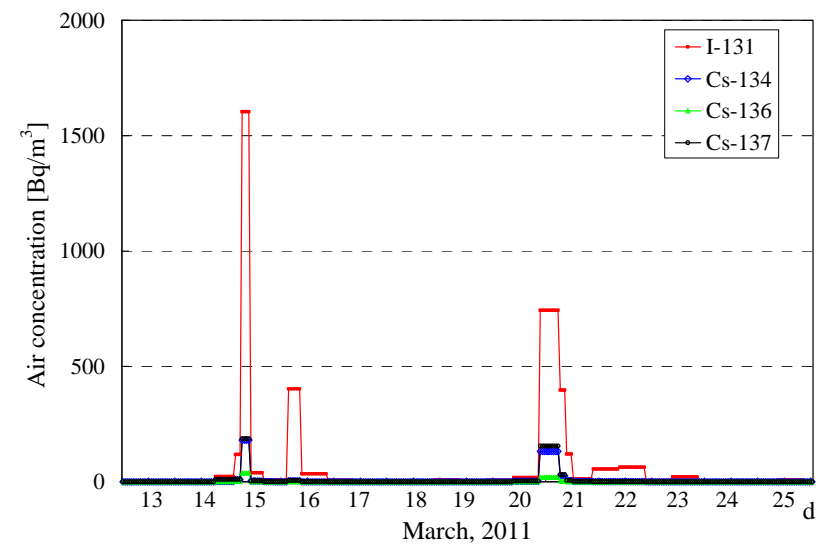

Figure 2. Temporal changes in the air concentrations of radionuclides (sum of particulate and gaseous forms).

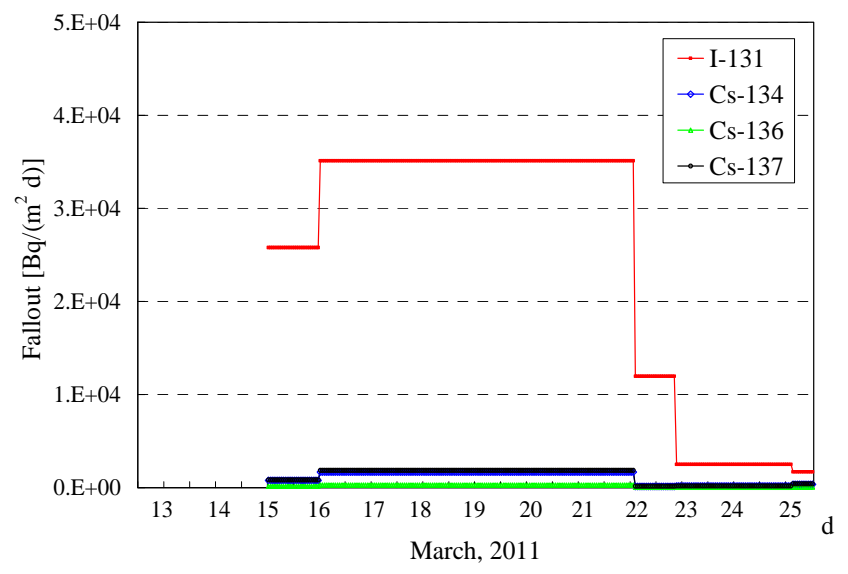

Figure 3. Temporal changes in the fallout of radionuclides.

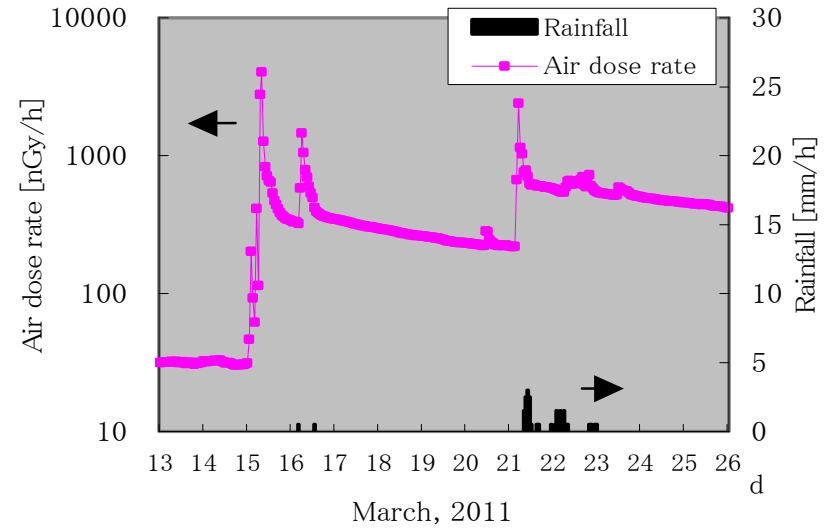

Figure 4. Temporal changes in the air dose rate measured and rainfall observed at the NCL.



Figure 5. Temporal changes in wind speed and direction observed at the height of $15 \mathrm{~m}$ above the ground at the NCL.

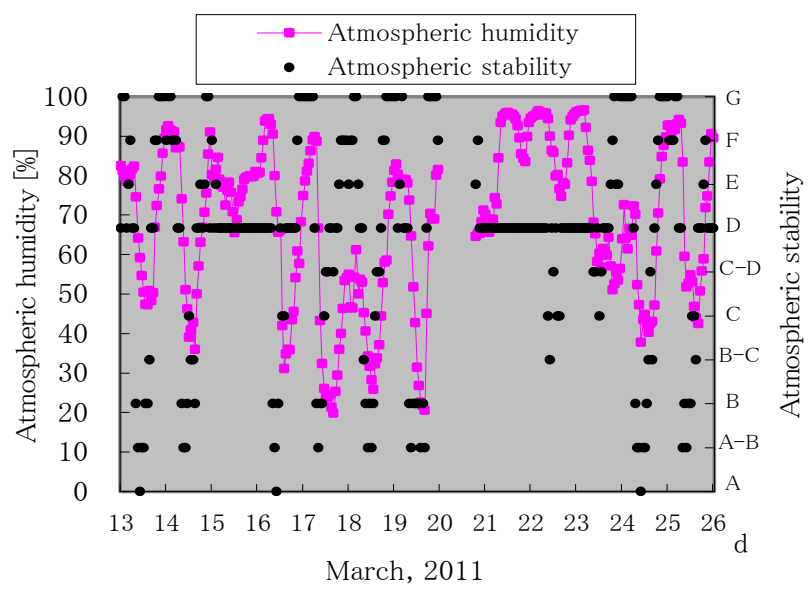

Figure 6. Temporal changes in atmospheric humidity and atmospheric stability at the NCL.

and the atmospheric stability. From Figures 4 and 5, while the wind blew from the north (1F-NPP) on 15, 16, and 21 March, the air dose rate increased with three peaks at 8 JST 15 March, 5 JST 16 March and 4 JST 21 March [3-4]. From this fact, the radioactive plumes reached the NCL at these dates. From the air concentrations and the fallouts measured during the two periods, that is, from 12 JST 15 March to 12 JST 16 
March (period 1) and from 12 JST 16 March to 14 JST 22 March (period 2), in which intervals the fallout samples were replaced at around 15, 16 and 21 March, the dry deposition velocities of radionuclides were estimated. The dry deposition velocity $(\mathrm{mm} / \mathrm{s})$ is defined as the fallout $\left(\mathrm{Bq} / \mathrm{m}^{2}\right)$ divided by the time integrated air concentration $\left(\mathrm{Bqh} / \mathrm{m}^{3}\right)$.

\section{Results and discussion}

\subsection{Estimation of dry deposition velocity}

Table 1 showed the time integrated air concentrations, the fallout and the estimated dry deposition velocities for the periods 1 and 2. As shown in Table 1, the dry deposition velocities for Iodine-131 (I-131), Cesium-134 (Cs-134), Cesium-136 (Cs-136) and Cesium-137 (Cs-137) were estimated to be in the order of $1 \mathrm{~mm} / \mathrm{s}$ for both periods.

Table 1. Time integrated air concentration, the fallout and the estimated dry deposition velocity for each radionuclide.

\begin{tabular}{|c|c|c|c|c|}
\hline \multicolumn{3}{|c|}{ Period number } & 1 & 2 \\
\hline \multicolumn{3}{|c|}{ Period } & $\begin{array}{l}12 \text { JST March } 15 \text { - } \\
12 \text { JST March } 16 \\
\end{array}$ & $\begin{array}{c}12 \text { JST March } 16 \text { - } \\
\text { 14JST March } 22 \\
\end{array}$ \\
\hline \multirow{16}{*}{$\begin{array}{c}\text { Time } \\
\text { integrated } \\
\text { air } \\
\text { concent- } \\
\text { ration } \\
\left(\mathrm{Bqh} / \mathrm{m}^{3}\right)\end{array}$} & \multirow{4}{*}{$\mathrm{I}-131$} & Patculate form & $7.9 \mathrm{E}+02$ & $4.6 \mathrm{E}+03$ \\
\hline & & Gaseous form & $2.0 \mathrm{E}+03$ & $5.6 \mathrm{E}+03$ \\
\hline & & Sum & $2.8 \mathrm{E}+03$ & $1.0 \mathrm{E}+04$ \\
\hline & & $\begin{array}{c}\text { Ratio of gaseous to } \\
\text { particulate forms }\end{array}$ & 2.6 & 1.2 \\
\hline & \multirow{4}{*}{ Cs-134 } & Patculate form & $4.1 \mathrm{E}+01$ & $1.3 \mathrm{E}+03$ \\
\hline & & Gaseous form & $4.6 \mathrm{E}+00$ & $5.0 \mathrm{E}+01$ \\
\hline & & Sum & $4.5 \mathrm{E}+01$ & $1.3 \mathrm{E}+03$ \\
\hline & & $\begin{array}{c}\text { Ratio of gaseous to } \\
\text { particulate forms }\end{array}$ & 0.11 & 0.04 \\
\hline & \multirow{4}{*}{ Cs-136 } & Patculate form & $7.5 \mathrm{E}+00$ & $1.9 \mathrm{E}+02$ \\
\hline & & Gaseous form & $6.8 \mathrm{E}-01$ & $6.5 \mathrm{E}+00$ \\
\hline & & Sum & $8.2 \mathrm{E}+00$ & $2.0 \mathrm{E}+02$ \\
\hline & & $\begin{array}{c}\text { Ratio of gaseous to } \\
\text { particulate forms }\end{array}$ & 0.09 & 0.03 \\
\hline & \multirow{4}{*}{ Cs-137 } & Patculate form & $4.9 \mathrm{E}+01$ & $1.5 \mathrm{E}+03$ \\
\hline & & Gaseous form & $4.5 \mathrm{E}+00$ & $5.9 \mathrm{E}+01$ \\
\hline & & Sum & $5.4 \mathrm{E}+01$ & $1.6 \mathrm{E}+03$ \\
\hline & & $\begin{array}{c}\text { Ratio of gaseous to } \\
\text { particulate forms }\end{array}$ & 0.09 & 0.04 \\
\hline \multirow{4}{*}{$\begin{array}{l}\text { Fallout } \\
\left(\mathrm{Bq} / \mathrm{m}^{2}\right)\end{array}$} & & I-131 & $2.6 \mathrm{E}+04$ & $2.1 \mathrm{E}+05$ \\
\hline & & Cs-134 & $7.8 \mathrm{E}+02$ & $1.0 \mathrm{E}+04$ \\
\hline & & Cs-136 & $1.6 \mathrm{E}+02$ & $1.8 \mathrm{E}+03$ \\
\hline & & Cs-137 & $8.3 \mathrm{E}+02$ & $1.1 \mathrm{E}+04$ \\
\hline \multirow{4}{*}{$\begin{array}{c}\text { Dry } \\
\text { deposition } \\
\text { velocity } \\
(\mathrm{mm} / \mathrm{s}) \\
\end{array}$} & & $\mathrm{I}-131$ & $2.6 \mathrm{E}+00$ & $5.7 \mathrm{E}+00$ \\
\hline & & Cs-134 & $4.8 \mathrm{E}+00$ & $2.1 \mathrm{E}+00$ \\
\hline & & Cs-136 & $5.4 \mathrm{E}+00$ & $2.5 \mathrm{E}+00$ \\
\hline & & Cs-137 & $4.3 \mathrm{E}+00$ & $1.9 \mathrm{E}+00$ \\
\hline
\end{tabular}

\subsection{Comparison of dry deposition velocities between radionuclides}

The dry deposition velocity for I-131 was estimated to be $2.6 \mathrm{~mm} / \mathrm{s}$, while those for Cs-134, Cs-136 and Cs-137 were estimated to be about $5 \mathrm{~mm} / \mathrm{s}$ for the period 1. The dry deposition velocity for I-131 was about half as large as those of Cs-134, Cs-136, and Cs-137. On the other hand, the dry deposition velocity for I-131 was estimated to be $5.7 \mathrm{~mm} / \mathrm{s}$, and those for Cs-134, Cs-136, and Cs-137 were estimated to be about $2 \mathrm{~mm} / \mathrm{s}$ for the period 2. The dry deposition velocity for I-131 was about three times larger than those of Cs-134, Cs-136, and Cs-137.

Table 1 showed the time integrated air concentrations of particulate and gaseous forms. From Table 1, the time integrated concentrations of the gaseous forms of I-131 were about two and a half times and about the same as large as those of the particulate forms for the periods 1 and 2, respectively. On the other hand, the time integrated concentrations of the gaseous forms of Cs-134, Cs-136 and Cs-137 were few for both the periods 1 and 2 .

The gas was composed of unreactive and reactive gases. The dry deposition velocity of unreactive gas is one-tenth smaller than that of aerosol, and that of reactive gas is ten times larger than that of aerosol [5]. When the ratio of unreactive and reactive portions of I-131 varies, the dry deposition velocity of I-131 varies. If the ratio was different between the Periods 1 and 2, the dry deposition velocities of I-131 for these periods I-131 would vary.

The dry deposition velocities for Cs-134, Cs-136, and Cs-137 were the same for the period 1. Also, the dry deposition velocities for these radionuclides were the same for the period 2. This reason seems to be that the chemical forms were almost the same among these radionuclides for each the period.

The dry deposition velocities of Cs-134, Cs-136, and Cs-137 on the period 2 were about half smaller than those of the period 1 .

The dry deposition velocity varies according to wind speed and atmospheric humidity [6]. From Figures 5 and 6 , the wind blew from the northeast direction, with the wind speed from 1.3 to $4.5 \mathrm{~m} / \mathrm{s}$ with the mean of $3.6 \mathrm{~m} / \mathrm{s}$, the atmospheric stability D (neutral), and the atmospheric humidity of $66.5 \%$ to $94.4 \% \mathrm{~m} / \mathrm{s}$ with the mean of $80.0 \%$ during the period 1 . On the other hand, the meteorological conditions varied largely during the period 2 because of the long period. The wind blew from north to south directions. The wind speed ranged from 0.2 to $8.2 \mathrm{~m} / \mathrm{s}$ with the mean of $3.1 \mathrm{~m} / \mathrm{s}$. The atmospheric stability ranged from A to G. The atmospheric humidity ranged from $19.8 \%$ to $96.4 \% \mathrm{~m} / \mathrm{s}$ with the mean of $64.1 \%$. From Figure 4, the large deposition during the period 2 occurred on 4 JST to 10 JST 21 March (period 2'). During the period 2', the wind blew from northeast direction, with the wind speed from 3.1 to $5.7 \mathrm{~m} / \mathrm{s}$ with the mean of $4.5 \mathrm{~m} / \mathrm{s}$, the atmospheric stability D (neutral), and the atmospheric humidity of $68.9 \%$ to $95.5 \% \mathrm{~m} / \mathrm{s}$ with the mean of $83.5 \%$. The wind speed during the period 2' was large compared to that during the period 1 . The wind direction, atmospheric stability and atmospheric humidity were almost the same between the periods 1 and 2'. Due to the large wind speed, the dry deposition velocities of Cs-134, Cs-136, and Cs-137 on the period 2 would become smaller.

The rainfall has a great effect to the deposition due to wet deposition. There was little rainfall in the period 1 , and the wet deposition did not influence to the deposition during the period 1 . On the other hand, some 
rainfall occurred from 8 JST 21 March to 8 JST 22 March on the period 2. So, the wet deposition might influence to the deposition during the period 2 .

\subsection{Comparison of dry deposition velocity with other study}

After the Chernobyl accident, which site was very far from the NCL compared to the 1F-NPP, the concentrations of I-131 in air and in the pasture were determined at NCL, and the dry deposition velocities were estimated by the same method as this paper [7]. The estimated dry deposition velocities of I-131 ranged from 1.3 to $17 \mathrm{~mm} / \mathrm{s}$ with the mean of $6.9 \mathrm{~mm} / \mathrm{s}$, and was in the same order as those of I-131 in this paper.

The Iodine-129 (I-129) had discharged from the Tokai Reprocessing Plant, and was determined by the environmental monitoring around the plant [8]. The I-129 is the same radioactive Iodine as I-131, and the chemical properties of these radionuclides seem to be the same. The estimated dry deposition velocities of I-129 ranged from 5 to $7.3 \mathrm{~mm} / \mathrm{s}$, and were also in the same order as that of I-131 for the period 2 in this paper.

Sehmel reviewed the papers about the particle and gas deposition and summarized the dry deposition velocities of many radionuclides and other than radionuclides under various meteorological and surface conditions [9]. In Sehmel's paper, the dry deposition velocities for Cs-137 were $0.3-1.5,-0.1-0.9$ and $2-5$ $\mathrm{mm} / \mathrm{s}$ for the deposition surface of water, soil and grass, respectively. The fallout sampler in this paper was prepared on the roof of the concrete building, and this building was surrounded by forest. If the deposition surface of this paper was assumed to be grass, the deposition velocities in this paper were the same as that in Sehmel's paper.

\section{Conclusion}

On the basis of the environmental radiation monitoring results at the NCL following the Fukushima Dai-ichi Nuclear Power Plant accident, the dry deposition velocities of radionuclides were estimated. As a result, the estimated dry deposition velocities for I-131, Cs-134, Cs-136 and Cs-137 were in the order of 1 $\mathrm{mm} / \mathrm{s}$, and were in the same order of those in other studies. The estimated dry deposition velocity varied according to the variations of the ratios of the particulate and gaseous forms of their radionuclides and meteorological conditions such as wind speed.

\section{References}

[1] G. Katata, M. Ota, H. Terada, M. Chino and H. Nagai, Atmospheric discharge and dispersion of radionuclides during the Fukushima Dai-ichi Nuclear Power Plant accident. Part 1: Source term estimation and local-scale atmospheric dispersion in early phase of the accident, J. Environ. Radioact. 109 (2012), pp. 103-113.

[2] G. Katata, H. Nagai, L. Zhang, A. Held, D. Serca and O. Klemm, Development of an Atmospheric-Soil-Vegetation Model for Investigation of Radioactive Materials Transport in the Terrestrial Biosphere, Progress in Nucl. Sci. and Technol. 2 (2011), pp.530-537.

[3] M. Takeyasu, M. Nakano, H. Fujita, A. Nakada, H. Watanabe, S. Sumiya and S. Furuta, Results of environmental radiation monitoring at the Nuclear Fuel Cycle Engineering Laboratories, JAEA, following the Fukushima Daiichi Nuclear Power Plant accidents, J. Nucl. Sci. Technol. 49 (2012), pp. 281-286.

[4] S. Furuta, S. Sumiya, H. Watanabe et al., Results of the Environmental Radiation Monitoring Following the Accident at the Fukushima Daiichi Nuclear Power Plant -Interim Report (Ambient Radiation Dose Rate, Radioactivity Concentration in the Air and Radioactivity Concentration in the Fallout), JAEA-Review 2011-035, Japan Atomic Energy Agency, (2011). [in Japanese]

[5] J. E. Till and H. A. Grogan, Radiological Risk Assessment and Environmental Analysis, Oxford University Press, New York, (2008), pp. 129-130, ISBN 978-0-19-512727-0.

[6] N. Yamagata, Environmental Radiation Handbook, Information Center Press, Tokyo, (1985), p. 257.

[7] M. Kinoshita, Summary Report on the Environmental Monitoring around Tokai Area following the Accident at Chernobyl Nuclear Power Plant, PNC TN8420-86-10, Power Reactor and Nuclear Fuel Development Corporation, (1986). [in Japanese]

[8] K. Shinohara, Measurement and behavior of ${ }^{14} \mathrm{C}$ and ${ }^{129} \mathrm{I}$ in the environment, J. Radioanal. Nucl. Chem. 260 (2004), pp. 265-271.

[9] G. A. Sehmel, Particle and gas deposition: A review, Atmos. Environ. 14 (1980), pp. 983-1011. 